\title{
Intuition and wisdom in decision making
}

\author{
Ivan Rocha Neto ${ }^{\text {a* }}$, Itiro lida ${ }^{\mathrm{b}}$ \\ aUniversidade Federal do Rio Grande do Sul, Porto Alegre, RS, Brasil \\ bUniversidade de Brasília, Brasília, DF, Brasil \\ *neto-ivan@hotmail.com
}

\begin{abstract}
Paper aims: This article discusses the importance of intuition and wisdom for timely andsuccessful decision making and highlights the features of intuitive leaders.

Originality: As engineers reach higher hierarchical levels, technical knowledge must be balanced with intuition, a matter that is not addressed in their education.

Research method: 1t is a theoretical essay illustrated by an example.

Main findings: Information is always incomplete and imperfect, and thus intuition plays a key role on effective decision making

Implications for theory and practice: It sheds light on the importance of intuition in decision making, which is not discussed in Engineering courses curricula. It also presents the example of Lynaldo Cavalcanti de Albuquerque, former President of the Federal University of Paraiba (UFPb) and the National Council of Scientific and Technological Development $(\mathrm{CNPq})$, who can be a role model of a effective decision maker, and a visionary and intuitive leader.
\end{abstract}

\section{Keywords}

Intuition. Wisdom. Education. Science and technology.

How to cite this article: Rocha Neto, 1., \& lida, 1. (2018). Intuition and wisdom in decision making. Production, 28, e20170007. https://doi.org/10.1590/0103-6513.20170007.

Received: Jan. 30, 2017; Accepted: Apr. 26, 2018.

\section{Introduction}

It is currently admitted that we are not as rational as once we supposed to be, and intuition is frequently used in decision-making. Intuition often proves itself a better counselor in decision-making than rational arguments or lengthy analyses. This occurs mainly in dubious, highly uncertain situations, within high uncertainty. The authors' experiences have shown that when we let rationality prevail over intuition, we frequently have regretted the outcomes. Learning acquired during our life gives us good advice. According Marius Usher (2016), professor at the University of Tel Aviv, intuition is reliable. The conclusion reached by a group of scientists led by him argues that reasoning is less successful than intuition or instinctive reactions. Scientific studies have confirmed that in $90 \%$ of cases, intuition has proved more reliable. "We cannot find enough reasons to trust, even if our intuition tells us that we should act differently" (Usher, 2016, p. 113).

Wiig (1993, p. 471), one of the founders of the discipline of Knowledge Management, wrote that "[...] people know more than they think, speak or write", or they are able to explain.

According Usher (2016), our mind saves and stores a multitude of experiences.

We all have met people with different personalities and have gone through good and bad situations. All those experiences are memorized, and sometimes we do not know why, but we have the feeling someone is unreliable, or something will not come out very well. This may happen because we have met someone with the same personality traits, and we realized that he/she was not a good person, or we have taken a similar decision, and it did not end well. Our mind saves a lot of valuable information and has an experience-based 
learning that contributes to tell us that intuition is reliable. There is a myriad of decisions that need to be taken and reasoning alone does not give enough support, it is also an act of confidence. Intuition makes decisions in a matter of seconds.

We experience it every day in very mundane things, such as "should 1 take the bus or subway?". We do not even use reasoning to take that decision, as we have done it so many times, we already know the best combination, so intuition decides it without much reflection. Let us think of someone who was born in the jungle and was raised far away from urban centers. If we take him/her to the city, he/she would not clearly know the best choice to make - to take the subway or bus - because he/she has never made that choice, or anything like that before, so learning has not been recorded in his/her mind (Usher, 2016).

Intuition is not something natural-born or magical. Smart people develop it during their life as they experience different situations. If we take an urban person with very good intuition to the jungle, he/she may feel less intelligent in that place. Instinct only works on with already learned situations, like to find food to survive, but we do not have the knowledge of someone who was raised in the jungle. We were born with innate instincts, such as survival and sexual reproduction.

Human beings avoid threats to their lifes without thinking about the decision, but we had to learn what can hurt us. If there is a fire close by, we do not let ourselves to be hurt. We learned that when children, because we were told that to be burnt hurts. Once we have learned what puts us in danger, the body reacts in a matter of seconds as a threat arises. Intuition is reliable, but we can only rely on it because we have perfected it from situations, books, movies, and other experiences. Many pieces of information are combined so we can reach the most appropriate decision to feel good. So, when it is time to make decisions, we should not dismiss our intuition, since it stores very reliable information. Our unexplained sensations in fact have a good explanation (Usher, 2016).

In his text Usher shows how sages take good decisions even from few data, information and knowledge, they are able to understand the context from their previous experiences.

Intuitive leaders know how to deal with uncertainties and therefore have learned to think, they usually think in a systemic and complex manner, replacing the Cartesian cause-and-effect relationships by observing interdependences, mutual influence among elements and variables, and the urgency, noting the properties that emerge from the whole and not necessarily from elements (Morin, 1990). Dee Hock (2009), who coined the concept of chaordic (chaos plus order) organizations and created Visa Credit Cards showed how decentralized decision making works. Intuitive leaders trust their team colleagues and bravely take the results of their decisions. They also do not' fear competent people, but trust and support the emergence of leaders, they prefer naturally constituted authorities to appointed ones.

\subsection{Previous experiences}

Intuitive leaders know how to evaluate earlier decisions that were successful in specific contexts, so as to not repeat the same solutions in new situations where success factors have changed. The Japanese say - "failure comes on the back of success", the two are so closely connected because the arrogance of success can lead to carelessness, which leads to failure. Visionaries are able to recognize change and make necessary adjustments to decide on a new situation. Successful people are those who do not forget to sow seeds that will guarantee success, they know how to cooperate and work as a team; to build mature and healthy personal and professional bonds; as well as to change and follow time evolution.

\subsection{Best managerial decisions}

Brazilian university courses usually deliver a lot of information to students, but do not teach them how to apply it appropriately, particularly in decision-making. Those decisions tend to be more complex and with higher uncertainty, especially at the higher ranks of companies.

At "technical" level tasks, decisions can be formalized in well-defined standards and rules. For example, the quality acceptance the criteria of a product in a production line can be clearly described. However, at higher levels in the organization hierarchy, those criteria become fuzzy. such as the design of a new product, purchasing of new machinery, material improvement, better productive process control, workforce qualification, among other aspects. Of course, there are no clearly defined rules for those decisions. In many cases, intuition becomes necessary. 
An engineer, at the beginning of his/her professional career, tends to work with well-defined decision criteria. These are contained in specifications, standards and principles, such as those used in a project. As one climbs up in the organizational hierarchy, decisions are made with higher uncertainty, like the one about the introducing a technological innovation or the opportunity to launch a new product on the market. Many professionals consider it natural to climb to positions with greater managerial responsibility, as they acquire experience in technical positions. However, one has to consider that managerial decisions can be very different from technical ones. To insist on applying the same scientific or technical criteria to managerial decisions can be disastrous.

That unsuccessful transition appears clearly in the management of public universities, where eminent scientists are driven to occupy top positions, as College directors of colleges or University Presidents. They usually insist on "scientific" decisions, requiring all the information related to the problem to be obtained and analyzed previously. This results in bureaucratic decisions, that are time-consuming and rarely innovative.

Several studies show a positive correlation between executives capable of intuitive decisions and the success of the companies they run. Those at senior management levels make greater use of intuition with success. The consultant Jose Carlos Mello participated in various technology transfer negotiations among multinational companies (verbal testimony, in 2015). On one side of the table sat foreign companies' representatives and on the other, those from the national companies. Exhibits, analyses and arguments were presented by qualified people. Many had master's and doctoral degrees and expressed themselves in various languages. However, the decision was usually taken by another person who did not have a scholar profile. This person generally had barely spoken, had difficulty to express himself, was a monoglot and had no important academic titles.

However, he listened to the arguments and had great power of synthesis, in addition to being very intuitive, had understood the scenario that was unfolded at the meeting. In many cases, he was not even able to explain the reasons for his own decisions.

There is no off- the- shelf rules ready to improve management decisions, however, one can put together some characteristics of successful managers. who occupied management positions successfully.

\subsection{Vision of the future}

A vision of the future is important to make decisions. It is constructed on the perception of the evolution of several factors, especially those related to the system's variables. This means that the manager should always be "tuned" into the evolution of the context in which he operates, including the trends in business environment, fashion, competitors, technology and legislation changes, and other activities. Some of those trends can convey future indicators. Analysis of past experiences can help in building the future scenarios, when the system is of a conservative type, that is, when the future will be a projection of the past. However, technology innovation often breaks that trend. Kodak is an example, it worked in analog photography with great success. However, it was not able to adapt to the digital photography era and went bankrupt. It detected that movement and attempted to migrate to the document copier business, but it also faced powerful competitors already established in that market. To have vision of the future is often not enough, and one must also take the necessary corrective measures in time.

\subsection{Intuition}

Formal engineering courses emphasize rational decision making and this tends to limit creativity and intuition. With computer development there has been a rapid increase in available information. At the same time, competition at all levels has increased the pressure for fast decision making. According to Ackoff (1989) information overload only confuses and disturbs timely decision-making.

However, decision-making based on past experiences can lead to failure, because of context shifts, and past solutions will not necessarily work in the future. Intuitive leaders know how to recognize the changing context and are able to envision opportunities to adopt innovative solutions. From the 1970s onwards, several studies were performed on intuition. High-level managers rarely adopt only rational behavior. Instead, these managers used intuition to reach a solution when facing unknown situations and complex problems, with high risk. Researchers Douglas Dean and John Mihalasky, from Newark School of engineering, have developed a test, called the PSI score, to evaluate the use of intuition in a sample of 67 American CEOs. The 60\% that had doubled the profits of their businesses in the last five years were all were above the average in the PSI score. Those who had not doubled their profits were all below average. The researchers concluded that one cannot assert that high PSI scores indicate obtaining profits, but its likelihood is increased with more intuitive people (Agor, 1986). 
Another study conducted by Weston Now (2012 apud Schultz, 2012), from the Master program in public Administration at the University of Texas, tested more than 2,500 managers from various hierarchical levels about the use of intuition in decision-making. He found that high-level managers had significantly better scores than those of middle and low level: "intuition seems to be a capacity more prevalent as we climbed the corporate hierarchy". Those high-level executives showed that they relied more on intuition to make decisions in critical situations. lsenberg (1999 apud Schultz, 2012) conducted similar studies with dozens of senior managers, with ten to thirty years in executive functions, in various industries. What he found was not exactly what he expected: although most of them admitted the need to perform technical analyses, in practice, they relied more on their intuition, especially in critical situations. Popularly, it is often said that women are more intuitive than men. In fact, tests have shown that women have a slight advantage. The explanation would be physical differences (men are bigger and stronger) and cultural repression (greater restriction on women). As a defense mechanism, women develop greater ability to recognize nuances and small details that men rarely acknowledge (Schultz, 2006). Women become more sensitive to non-verbal communication, paying more attention to visual and audible signals, such as facial expressions, gestures, colors, tones of voice and how people look at each other.

Therefore, intuition plays a key role in the decision-making process, especially within uncertainty. However, it must be combined with other factors, such as experience, knowledge of the problem, and careful analysis of pros and cons.

\subsection{Urgency and importance}

Urgent decisions compete with those that are more important. Good managers seek to preserve part of their time for important decisions. This means, generally, replacing improvisation with planning, to act in advance. Problem must be solved before they grow and "burst" into several small ones. It is like the farmer who must exterminate the weed before it releases seeds and spreads out on the field. A good manager is one who makes decisions in advance to prevent future difficulties. Of course, anticipating decisions requires a sense of urgency. It is necessary to balance importance and urgency, and not act as someone who applies corrective measures to urgent, and never has time to manage the really important problems. Matus (1993) analyzed 3,000 decisions taken by a South American ruler, and classified them in four groups, according the importance of the subject. He found that only five of them could be classified as very important, representing $0.2 \%$ of the total (Table 1 ). Most of those decisions (88.3\%) could be classified as routine or emergency ones. Emergency may be more time consuming than important decisions. To make things worse, the leader makes poor quality decisions because he does not master the necessary knowledge on those urgent decisions, which may involve, for example, knowledge on the process. Those decisions could be delegated to the lower level employees, specialized technicians who could give more adequate solutions.

Table 1. Distribution of decisions taken by a South American ruler, according their degree of importance (Matus, 1993).

\begin{tabular}{lcc}
\hline \multicolumn{1}{c}{ Degree of importance } & Quantity & $\%$ \\
\hline Very important decisions & 5 & 0.2 \\
Important decisions & 45 & 1.5 \\
Significant decisions & 300 & 10 \\
Routine decisions & 2,650 & 88.3 \\
Total & 3,000 & 100 \\
\hline
\end{tabular}

\subsection{Information selection}

Currently there is a lot of information available on almost any subject. Of course, the leader do not have time to gather and analyze all that information. He needs to choose those most relevant for each case. In addition, that manager has no time to read extensive projects, analyses, opinions or reports. The leader must create filters so that only relevant and reliable information reaches him in each case to take the decision. He must be very careful not to rely on incomplete, biased or false information.

To avoid the distortions caused by those filters, one can go straight to the information sources. For example, a major producer of US winery used to receive sales reports six months late, because it had to go through five or six agents in the distribution chain. That period was too long to take corrective measures such as special sales to lower stocks. The manager could call customers directly (retailers and restaurants) to obtain first-hand information from demand sources. When information comes in written reports, the manager may ask a qualified person for his/her opinion. If that is the case, one can refer to more than one specialist, with divergent or even 
opposing views to form their own opinion. In political parlance, this means listening to both the situation and the opposition. In the case of verbal advice, there is a risk of receiving biased information. There are many situations when subordinates omit negative information, pretending that everything is fine and influencing the leader to take bad decisions. In addition to oral information, we transmit a lot of information by the body expressions and of non-verbal communication, such as facial expressions, gestures and postures. This nonverbal information is considered more reliable (Ekman, 2011). There are computer programs that can identify facial expressions and associate them to different emotions. Researchers at Ohio State University have developed an application able to interpret up to 21 emotions such as happiness, sadness, anger, disgust and others, by facial expressions. There are some people, mostly women, who refuse to close the deal when they discover that there is lack of coherence and harmony between the non-verbal communication of a person and his words (Ekman, 2011).

As a general rule the manager, having little time available, should not receive long reports to read. There must be an assistant to make prior analysis and elaborate more succinct recommendations.

\subsection{Timing}

Decisions should be taken as quickly as possible. In most cases, quick decisions, even at the risk of making mistakes, are considered better than good but time-consuming ones. When a decision is made, the process moves and errors can be corrected and that, of course, is better than being paralized. Errors should be detected quickly so that they can be immediately corrected. One can avoid the paralysis caused by extensive analyses and diagnoses. In practice, there is no qualitative difference between quick and slow decisions. When it is discovered that a slow decision was wrong, it usually takes a long time to fix it, and it may create many problems.

In some situations, people are specially trained to take quick decisions. For example, at NASA the space flight controllers should take a decision every 20 seconds, getting information from up to 200 different sources. In some critical stages, such as those moments preceding a rocket launch, they must take a decision every 3 seconds, based on 50 to 60 pieces of information. The training of those controllers includes simulated failures that could lead them to take wrong decisions. In all those cases, each controller has to use experience and intuition.

Similar situations are experienced by doctors in emergency rooms (Schultz, 2006). Medicine is not an exact science, and each treatment is based on examinations and diagnoses, analysis, experience and intuition of the doctor. The emergency room of Bellevue Hospital in New York serves around 300 patients per day (Schultz, 2006). In many cases, there is no precise diagnosis and problems should be solved as soon as they appear, based on fragmented information. This was the case of a woman who complained of chest pain. Electrocardiograms and several other tests were done which indicated no anomalies. By intuition, the doctor in charge decided to send her to the Intensive Care Unit (ICU). A few hours later she had a massive heart attack and would probably have died if she had not been rapidly treated at the $\mathrm{ICU}$.

Intuition can manifest itself quickly, in just a few seconds. A person can form an opinion of another, only by seeing him, even if he have not said anything. It is like enjoying a wine: its color, aroma and taste are experienced at the first sip.

There is a more appropriate occasion to make a decision, depending on the circumstances. Premature decisions can be misunderstood and may not find fertile soil to thrive. Late decisions may produce little effect, because the opportunity has been lost. To adjust timing, the leader can follow business indicators evolution. For example, there are professionals who follow commodity prices and become able to decide on their investments. In the early 1950s, the baby boom phenomenon provided many business opportunities for products and services for children, such as diapers, cribs, carriages, kindergarten and so on. However, that was an opportunity that passed and required the investment to be made at the right time.

Therefore, the leader must be patient to wait for the right time to act. On the other hand, when an opportunity arises, he/she must act quickly to avoid losing the time. Those opportunities may occur cyclically or randomly. The good leader must always be prepared for when arise. For example, in universities, opportunities may arise for purchasing books for the library at the end of the year. Often, the time limit for the submission of applications is very short. In this case, the leader must have a list of books "waiting in the drawer" to not miss the opportunity.

An inevitable consequence of an increasing awareness on intuition for decision making will be its incorporation into mainstream management education. Researchers and practitioners can look forward to a time when the notion of intuition is not only a valid, reliable and well-theorized construct, with firm empirical foundations, but is also recognized and accepted as an indispensable element of the competence base of the successful business executives (Hodgkinson et al., 2009).

The time for a science of intuition in organizations, capable of guiding practice and improving effectiveness has come. Although intuition is frequently ascribed to transcendental quality, it is real. It is important for 
organizational effectiveness and the management science should contribute through more and rigorous research into the nature and development of intuitive decision-making skills, and how people detect coherent patterns in complex environments. It is how they create solutions that work within time limits. In addition, expert (or knowledge-based) intuition can be acquired through experience. These factors indicate that the management sciences should pay more attention to a broader range of cognitive processing factors in organizational contexts (Salas et al., 2010).

\subsection{An example}

Public services in Brazil are characterized by bureaucracy and slowness. This is caused not only by excessive regulation, but also by those at key positions who are not willing to make decisions. They avoid personal responsibility by decision. Many of them avoid it by putting the decision burden on collegiate decision, claiming democratic practices. Those "democratic" decisions are usually very time-consuming and are not always the most effective, as compared with individual decisions, assuming good preparation and responsibility. Some general decisions require consensus and should be taken in committees. However, most management decisions could be taken by the person in charge.

Lynaldo Cavalcanti is as a notable exception in the public service. He occupied several positions, in the decades of 1960 to 80, including the director of the Polytechnic School at Campina Grande, president of the Federal University of Paraiba (UFPb), president of the National Council of Scientific and Technological Development (CNPq) and president of the Council of Brazilian Universities (CRUB). In addition, he served as Director of University Affairs (DAU) at the Ministry of Education (Rocha Neto, 2010).

He was also founder of ABIPTl, the Brazilian Association of Technological Research Institutions, having worked for about 15 years as Executive Secretary. Lynaldo can be considered an example of chaordic leadership, as will be shown, a leader with decision-making capacity and a reference for current leaders (Rocha Neto, 2010). People who worked with him describe his many qualities, with emphasis on the following points:

- He was always very well informed, both by formal and informal channels. He used to check the information from various sources, reducing bias;

- When receiving new information, he quickly realized if it what was important, essential, basic or critical, not getting carried away by details or platitudes;

- For important affairs, he worked with redundancy, building parallel paths and, sometimes even with opposing opinions, asking for the same information from different sources;

- For each type of subject, he had a trusted person, who he consulted before deciding, an informal network of personal information;

- He had a privileged memory, allowing him to make connections with other information (other projects, people and institutions) and past performances;

- He worked with few alternatives; two or three, at most;

- He was very quick to make decisions, with intuition and courage;

- When taking decisions, he had already planned the next step for its implementation;

- He sought to stay informed about tasks and projects executions, taking quick corrective action, when needed;

- He enjoyed human potential, giving emphasis to the interests of each person, if they were compatible with the institutional objectives;

- He had a certain rebelliousness, nonconformity and the courage to challenge the status quo.

These qualities led him to occupy various positions in public administration. He was a visionary in the early 1980s, raising the issue of innovation, when nobody spoke on the subject in science or technology fields in Brazil.

As Chairman of CNPq he created the Programs for Scientific and Technological Development to promote the technologies of the future (Biotechnology; Information Technology; and Environmental Technologies).

Although a civil engineer with no master or doctor titles, he gathered professors and doctors to implement his programs, both at CNPq, at Federal University of Paraiba and other institutions. He was recognized by many as a visionary, able to propose innovative ideas, which are still applied in the national system of science, 
technology and innovation. All those who lived or worked with him were impressed about his vision of the future. In general, his decisions were made intuitive, he did not know how to explain them just stating how he felt. In fact, he spoke little and did not specify how to meet his demands, betting on the ambiguity of ideas and creativity of his employees. (Rocha Neto, 2010)

He once asked lvan Rocha Neto to travel to the Aeronautics Technological Institute (ITA), Brazil's military aeronautics engineering school, and "to save it" from competition from private institutions, who were taking away the best researchers and lecturers. He did not specify how, but decided to support that important institution. The result was the granting of research scholarships for many of the lecturers. That action caused unrest in the scientific community, but he kept his decision. This example features his vision of the future and the sense of urgency that accompanied him throughout his life as a manager.

He created a Superintendence of Institutional Programs (SPI) at CNPq, which previously only dealt with individual researchers and launched the national Programs of Genetic Engineering and Biotechnology, Chemistry, Geosciences, Procurement of Reagents, Electronic Instrumentation, and Support for Emerging Groups. Later, many of those programs composed the Scientific and Technological Development Support Program (PADCT), which obtained a loan from the World Bank, gathering agencies and bodies to promote scientific and technological development, which inspired the later creation of the Ministry of Science and Technology (MCT).

CNPq technicians went on to adopt planned public bidding processes for financing of new projects, in accordance with clearly established priorities, replacing the old practice of demand without defining priorities.

Another example of the sense of urgency and importance of his decisions was the process expansion of UFPb into the inner cities, founding campi in major cities in Paraiba. According Paulo Melo (see Rocha Neto, 2010), one of the leading, if not the first, of Lynaldo's concerns about UFPb was precisely changing the profile of its faculty, by taking two measures, both bold and courageous for their time: bringing masters and doctors, many of whom were marginalized by the military regime and sending professors for graduate studies in Brazil and abroad. It was a revolutionary, with such qualifications, open-mindedness and more acute critical sense, the ability to better reflect and opine about facts, the profile of the headquarters in João Pessoa began to change, and a new cultural environment was set. That did not prevent some xenophobia, especially for those who suddenly saw their position as opinion makers threatened.

As witnessed by Álvaro Braga in Rocha Neto (2010), as an executive, Lynaldo was "the man". He always relied on confidence, on responsibility and on developing the creativity of his employees, whom he always treated with great respect. As ltiro lida highlighted, "only rarely have 1 seen an executive acting as quickly and intuitively (Rocha Neto, 2010). While others thought about planting one tree, he grew an entire forest. Some seeds died as always happens with innovative ventures, but the chances of many to survive where great. He worked also with parallel subsystems, creating redundancies. By doing so, he divided and shared uncertainty. Above all, he always relied on people. Method, intuition, permanent information collection and, above all, confidence in people and in their employees. Who does not remember the action lists with keywords, written and scratched, updated throughout the day, piles of paper arranged and hand written at all times. Short phone calls, horror to details and gossip, long and boring explanations. As Alvaro Braga and ltiro lida report in Rocha Neto (2010), his dispatches were marked by informality and little conversation, which caused irritation and criticism from some people.

At ABIPTI, he intuitively, even without knowing its theoretical foundations, implemented an innovative management model. Ivan Rocha Neto ranks this as chaordic management (chaos plus order), inspired by Dee Hock. The recommendations of this author coincide almost entirely in practice and style with those that he implemented.

The protection of employees from the military regime was one of the hallmarks of his administration both at UFPb and CNPq. He counted on the skills of masters and doctors whom he contacted across the country and abroad. Although he had no other academic qualifications, he knew whom to ask, forming a large network of collaborators that helped to take timely decisions.

\section{Final considerations}

Lynaldo's work was recognized both at home and abroad, and he earned titles of Doctor Honoris Causa in Brazilian and foreign Universities. Imitations are rarely successful, but the example of Lynaldo's professional life can certainly serve as a reference for young engineers and professionals who will become leaders. His aversion to bureaucracy must also serve as an inspiration for the formation of public managers. Those are the authors expectations in writing this text. 


\section{References}

Ackoff, R. L. (1989). From data to wisdom. Journal of Applied Systems Analysis, 16, 3-9.

Agor, W. H. (1986). The logic of intuitive decision making: a research based aproach for top management. New York: Quorum Books. Ekman, P. (2011). A linguagem das emoções. São Paulo: Lua de Papel.

Hock, D. (2009). O nascimento da era caórdica. São Paulo: Cultrix.

Hodgkinson, G. P., Sadler-Smith, E., Burke, L. A., Claxton, G., \& Sparrow, P. R. (2009). Intuition in organizations: implications for strategic management. Long Range Planning, 42(3), 277-297. http://dx.doi.org/10.1016/j.lrp.2009.05.003.

Matus, C. (1993). Política, planejamento e governo (Série IPEA, No. 143). Brasília: IPEA.

Morin, E. (1990). Introduction à la pensée complexe. Paris: EST Éditeurs.

Rocha Neto, 1. (2010). Lynaldo Cavalcanti: além das palavras. Brasília: Paralelo 15.

Salas, E., Rosen, M., \& Granados, D. (2010). Expertise-based intuition and decision making in organizations. Journal of Management, 36(4), 941-973. http://dx.doi.org/10.1177/0149206309350084.

Schultz, R. (2006). Behaviral theories and neurophysiology of reward. Annual Review of Psychology, 57(1), 87-115. http://dx.doi. org/10.1146/annurev.psych.56.091103.070229. PMid:16318590.

Schultz, R. (2012). Sabedoria e intuição (7. ed.). São Paulo: Cultrix.

Usher, M. (2016). Economic irrationality is optimal during noisy decision making. In Proceedings of the National Academy of Sciences of the United States of America. Washington: PNAS.

Wiig, K. (1993). Knowledge management foundations: thinking about thinking: how organizations create, represent and use knowledge. Arlington: Schema Press. 